\title{
An Experimental Investigation on the Properties of Concrete Using Copper Slag as a Partial Replacement of Fine Aggregate
}

\author{
Mannala Jyothi ${ }^{1}$, A. B. S. Dadapeer ${ }^{2}$, Dr. C. Ramachandrudu ${ }^{3}$ \\ ${ }^{*}$ M.Tech, St.Mark Eucational Institution Society Group of Institutions, Anantapur, Andhra Pradesh, India \\ *2Assistant Professor, Professor ${ }^{3}$, Civil Engineering Department, Chiranjeevi Reddy Institute of Engineering \& \\ Technology, Anantapur, Andhra Pradesh, India
}

\section{ABSTRACT}

Now a days, infrastructure development holds the key for the development of every nation. Concrete is one of the most utilized material by the construction industry which is a homogeneous material prepared of heterogeneous materials like Cement, sand and aggregates. However rapid urbanization has created a huge demand for natural sand hence made it even more expensive. This led the researchers to find other materials which could be used as a replacement of sand whose main chemical composition is Silica (SiO2). After a great extent of research, researchers found that materials like Stone dust, Copper Slag, Coal Fly Ash, Carbonate Sand etc. having silica composition could be used as a replacement of sand. The Present experimental investigation is carried out for M20 grade of concrete mixes with partial replacement of Fine Aggregate (Sand) with Copper Slag. Compressive Strength and Split Tensile Strength at the ages of 7, 28 days for various combinations of Copper Slag and Sand were investigated. Sand was replaced with Copper Slag by 0\%,10\%, 30\%, and 50\%.

Keywords : Copper Slag, Fine Aggregate, Compressive Strength, Split Tensile Strength and Replacement

\section{INTRODUCTION}

The utilization of industrial waste or secondary materials has encouraged the production of cement and concrete in construction field. Newby-products and waste materials are being generated by various industries. Dumping or disposal waste materials causes environmental and health problems. Therefore, recycling of waste materials is a great potential in concrete industry. For many years, by-products such as fly ash, silica fume and slag were considered as waste materials. Concrete prepared with such materials showed improvement in workability and durability compared to normal concrete and has been used in the construction of power, chemical plants and under-water structures. Over recent decades, intensive research studies have been carried out to explore all possible reuse methods. Construction waste, blast furnace, steel slag, coal fly ash and bottom ash have been accepted in many places as alternative aggregates in embankment, roads, pavements, foundation and building construction, raw material in the Manufacture of ordinary Portland cement pointed out by Teik thye luin et al (2006). Copper slag is an industrial by-product material produced from the process of manufacturing copper. For every ton of copper production, about 2.2 tons of copper slag is generated. It has been estimated that approximately 24.6 million tons of slag are generated from the world copper industry (Gorai et al 2003). Although copper slag is widely used in the sandblasting industry and in the manufacturing of abrasive tools, the remainder is disposed of without any further reuse or reclamation. Copper slag possesses mechanical and chemical characteristics that qualify the material to be used in concrete as a partial replacement for Portland cement or as a substitute for aggregates. For example, copper slag 
has a number of favorable mechanical properties for aggregate use such as excellent soundness characteristics, good abrasion resistance and good stability reported by (Gorai et al 2003).

\section{BACKGROUND OF COPPER SLAG}

Sterlite Industries India Limited (SIIL), Tuticorin, Tamil Nadu is the principal subsidiary of Vedanta Resources public limited company(PLC), a diversified and integrated FTSE 100 metals and mining company, with principal operations located in India and Australia. The annual turnover of SIIL, Tutucorin, India is Rs.13, 452 crores.SIIL, a leading producer of copper in India, pioneered the manufacturing of continuous cast copper roads and established India's largest copper smelting and refining plant for production of world class refined copper. SIIL is the producer of copper slag (Figure 1.1) during the manufacture of copper metal. Presently, about 2500 tons of copper slag is produced per day and a total accumulation of around 1.5 million tons.

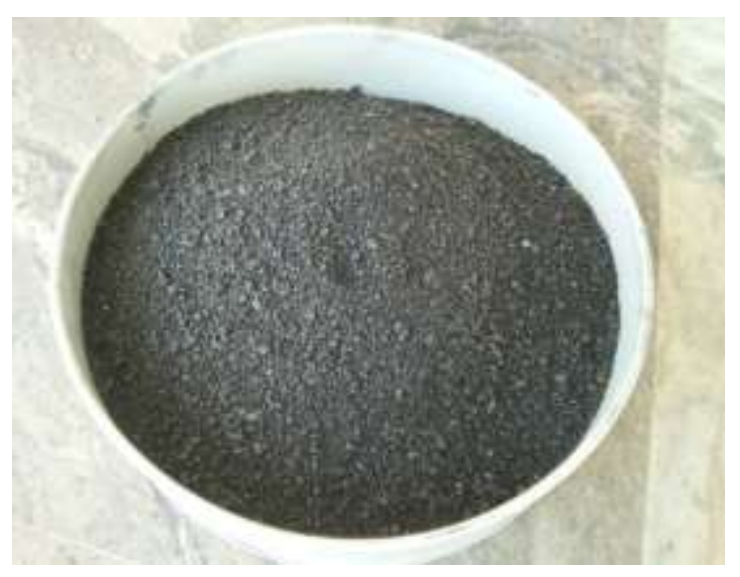

Fig 1. Appearance of copper slag sample

This slag is currently being used for many purposes. It is a glassy granular material with high specific gravity particle sizes. The various myths about copper slag is shown in Table 1.1. The size of the particle is of the order of sand and can be used as a fine aggregate in concrete. To reduce the accumulation of copper slag and also to provide an alternative material for sand and cement, an approach has been done to investigate the use of copper slag in concrete for the partial replacement of sand and cement.

TABLE 1.1 Properties of copper slag

\begin{tabular}{|c|c|}
\hline S.No & Properties \\
\hline 1 & Non-toxic material \\
\hline 2 & High durability \\
\hline 3 & Improves concrete strength \\
\hline 4 & $\begin{array}{c}\text { No bleeding of concrete up to } 40-50 \% \\
\text { replacement }\end{array}$ \\
\hline 5 & Leaching levels are insignificant \\
\hline
\end{tabular}

\subsection{PRODUCTION OF COPPER SLAG}

Copper slag is a by-product obtained during the matte smelting and refining of copper has been reported by Biwa's and Davenport (2002). The major constituent of a smelting charge are sulphides and oxides of iron and copper. The charge also contains oxides such as $\mathrm{SiO} 2, \mathrm{Al} 2 \mathrm{O} 3 \mathrm{CaO}$ and $\mathrm{MgO}$, which are either present in original concentrate or added as flux. It is Iron, Copper, Sulphur, Oxygen and their oxides which largely control the chemistry and physical constitution of smelting system. A further important factor is the oxidation/reduction potential of the gases which are used to heat and melt the charge stated by Gorai et al (2002). As a result of this process copperrich matte (sulphides) and copper slag (oxides) are formed as two separate liquid phases. The addition of silica during smelting process forms strongly bonded silicate anions by combining with the oxides. This reaction produces copper slag phase, whereas sulphide from matte phase, due to low tendency to form the anion complexes. Silica is added directly for the most complete isolation of copper in matte which occurs at near saturation concentration with $\mathrm{SiO} 2$.The slag structure is stabilized with the addition of lime and alumina. The molten slag is discharged from the furnace at $1000-1300^{\circ} \mathrm{C}$. When liquid is cooled slowly, it forms a dense, hard crystalline 
product, while a granulated amorphous slag is formed through quick solidification by pouring molten slag.

\subsection{USE OF COPPER SLAG IN VARIOUS FIELDS}

\subsubsection{Use of Copper Slag in Cement Clinker Production}

Since the main composition of copper slag is vitreous FeSio3, it has low melting point and could reduce the calcination temperature for cement clinker. Thus, the use of copper slag to replace iron powder as iron adjusting material facilitates cement production and reduces or eliminates the need of mineralizes has been pointed out by (Huang 2001). The performance testing results indicated that cement produced by using copper slag performed even better than using iron powder.

\subsubsection{Use of Copper Slag in Blended Cement}

The use of copper slag as a pozzolanic material for ordinary Portland cement and its effects on the hydration reactions and properties of mortar and concrete have been reported in several applications (Al-Jabri et al2006, Tata et al 2007, Malhotra 1993, Tixier et al 1997, Ariro and mobasher1999). The copper slag incorporation into the cement mortar does not cause an increase in the leached elements reported by Sanchez de Rojas et al (2004).Another work showed that the amounts of leached elements of copper slag are significantly lower than the regulatory levels determined by United States Environmental Protection Agency (USAPA) (Alter 2005). Arino and mobasher (1999) suggested that up to $15 \%$ of copper slag can be used as a cement replacement with constant $\mathrm{w} / \mathrm{c}$ ratio of 0.4 . This gives higher compressive strength than ordinary cement.

The materials used in the present investigation and their properties are briefly discussed below.

\subsection{CEMENT}

An OPC 43 Grade Sankar cement was used in this investigation. The quantity required for this work was assessed and the entire quantity was purchased and stored properly in casting yard. The following tests were conducted in accordance with IS codes.

1. Specific gravity (Le - Chatelier flask) (IS: 17271967)

2. Standard consistency (IS: 4031 - 1988 Part 4)

3. Initial setting time (IS: 4031 - 1988 Part 5)

4. Final setting time (IS: 4031 - 1988 Part 5)

\subsubsection{SPECIFIC GRAVITY (LE - CHATELIER FLASK) (IS: 1727-1967)}

\section{PROCEDURE:}

Specific gravity of pozzolona shll be determined on the material as received, unless otherwise specified. Fill the flask with kerosene or naptha to a point on the stem between the zero and the $1 \mathrm{ml}$ mark and replace the stopper. Then immerse the flask in a constant temperature water bath, maintained at about room temperature for sufficient interval to avoid greater than $\pm 0.2^{\circ} \mathrm{C}$ in the temperature of the liquid in the flask. Take the reading of the liquid in the flask. Introduce a weighed quantity of pozzolona into flask, taking care that no portion of it adhere to the inside of the flask above the liquid, by slightly vibrating the flask. Replace the stopper and roll the flask in an inclined position to expel any bubble in the pozzolona, the level of the liquid will be in its final position at some point of the upper series of graduations. The reading shall be taken after the flasks immersed in the eater bath.

\subsubsection{STANDARD CONSISTENCY (IS: 4031 - 1988 PART 4)}

\section{PROCEDURE}

The standard consistency of a cement paste is defined as that consistency which will permit the Vicat 
plunger G shown in IS : 5513-1 976*to penetrate to a point 5 to $7 \mathrm{~mm}$ from the bottom of the Vicat mould when the cement paste is tested as described in 5.2 to 5.4. Prepare a paste of weighed quantity of Cement with a weighed quantity of potable or distilled water, taking care that the time of gauging is not less than 3 minutes, nor more than $5 \mathrm{~min}$, and the gauging shall be completed before any sign of setting occurs. The gauging time shall be counted from the time of adding water to the dry cement until commencing to fill the mould. Fill the Vicat mould E with this paste, the mould resting upon a non-porous plate. After completely filling the mould, smoothen the surface of the paste, making it level with the top of the mould. The mould may be slightly shaken to expel the air. Clean appliances shall be used for In filling the mould, the operator's hand on the blade of the gauging trowel shall alone be used.

\subsubsection{Initial setting time (IS: 4031 - 1988 Part 5) Determination of Initial Setting Time}

Place the test block confined in the mould and resting on the non-porous plate, under the rod bearing the needle $(C)$; lower the needle gently until it comes in contact with the surface of the test block and quickly release, allowing it to penetrate into the test block. In. the beginning, the needle will completely pierce the test block. Repeat this procedure until the needle, when brought in contact with the test block and released as described above, fails to pierce the block beyond5.0 $\pm 0.5 \mathrm{~mm}$ measured from the bottom of the mould. The period elapsing between the time when water is added to the cement and the time at which the needle fails to pierce the test block to a point $5.0 \pm 0.5 \mathrm{~mm}$ measured from the bottom of the mould shall be the initial setting time.

\subsubsection{FINAL SETTING TIME (IS: 4031-1988 PART5) Determination of Final Setting Time}

Replace the needle $(C)$ of the Vicat apparatus by the needle with an annular attachment $(F)$.The cement shall be considered as finally set when, upon applying the needle gently to the surface of the test block, the needle makes an impression thereon, while the attachment fails to do so. The period elapsing between the time when water is added to the cement and the time at which the needle makes an impression on the surface of test block while the attachment fails to do so shall be the final setting time. In the event of a scum forming on the surface of the test block, use the underside of the block for the determination.

\section{PHYSICAL PROPERTIES OF COPPER SLAG}

Copper slag is black glassy and granular in nature and has a similar particle size range like sand. The specific gravity of Indian slag lies between 3.4 and 4.1 . The bulk density of copper slag varies between 1.9 to 2.15 $\mathrm{kg} / \mathrm{m} 3$ which is almost similar to the bulk density of conventional fine aggregate. Table 4.4 shows physical properties of copper slag. The free moisture content present in slag was found to be less than $0.5 \%$. Gradation test was conducted on copper slag and sand showed that both copper slag and sand had comparable particle size distribution as shown in Table 4.4 However, it seems that sand has higher fines content than copper slag. Tests to determine specific gravity and water absorption for copper slag and sand were carried out in accordance with ASTM C128. The results presented in Table 4.2 shows that copper slag has a specific gravity of 3.91which is higher than that of sand (2.57) and OPC (3.12) which may result in production of HPC with higher density when used as sand substitution. Table 4.4 shows sieve analysis report for various proportions of sand by copper slag. Table 4.4 shows that the measured water absorption for copper slag was $0.16 \%$ compared with 
$1.25 \%$ for sand. This suggests that copper slag would demand less water than that required by sand in the concrete mix. Therefore, it is expected that the free water content in concrete matrix will increase as the copper slag content increases which consequently will lead to increase in the workability of the concrete. The presence of silica in slag is about $26 \%$ which is desirable since it is one of the constituents of the natural fine aggregate used to normal concreting operations. The fineness of copper slag after grinding was calculated as $125 \mathrm{~m} 2 / \mathrm{kg}$.

\section{COMPACTING}

The test specimens are made as soon as practicable after mixing and in such a way as to procedure full compaction of the concrete with neither segregation not excessive laitance. The concrete is filled in to the mould in layers approximately $5 \mathrm{~cm}$ deep.

\subsection{Compacting by variation}

When compacting by vibration, each layer is vibrated by means of an electric or pneumatic hammer or vibration or by means of a suitable vibrating table until the specified condition is attained. The mode and quantum of vibration of the laboratory specimen shall be as nearly the same as those adopted in actual concerting operations. Care must be taken while compacting high slum concrete, which is generally placed by pumping. If care it's not taken severe segregation takes places in the mould, which results in low strength when specimen are crushed. The specimen crushing strength of concrete.

\subsection{CURING}

Because the cement requires time to fully hydrate before it acquires strength and hardness, concrete must be cured once it has been placed. Curing is the process of keeping concrete under a specific environmental condition until hydration is relatively complete. Good curing typically considered to use a moist environment which promotes hydration ,since increased to use a moist environment which promotes hydration, since increased hydration lowers permeability and increase strength, resulting in a higher quality material. Allowing the concrete surface to dry out excessively can result in tensile stress, which the still-hydration interior cannot with stand ,causing the concrete to crack. Also the amount of heat generated by the chemical process of hydration can be problematic for very large placements. Allowing the concrete to freeze in cold climates before the curing is complete will interrupt the hydration process, reducing the concrete strength and leading to scaling and other damage of failure.

\section{EXPERIMENTAL PROCEDURES}

\subsection{Compressive Strength Test}

Concrete cubes of size $150 \mathrm{~mm} \times 150 \mathrm{~mm} \times 150 \mathrm{~mm}$ were cast with and without copper slag. During casting, the cubes were mechanically vibrated using a table vibrator. After 24 hours, the specimens were demoulded and subjected to curing for 28 days in portable water. After curing, the specimens were tested for compressive strength using compression testing machine of $2000 \mathrm{KN}$ capacity. The maximum load at failure was taken. The average compressive strength of concrete and mortar specimens was calculated by using the following equation 5.1.

$$
\frac{\text { Compressive strength }\left(\mathrm{N} / \mathrm{mm}^{2}\right)=}{\text { ulimate comprssive load }(\mathrm{N})}
$$

The tests were carried out on a set of triplicate specimens and the average compressive strength values were taken.

\subsection{Split Tensile Strength Test}

Concrete cylinders of size $150 \mathrm{~mm}$ diameter and $300 \mathrm{~mm}$ length were cast with incorporating copper slag as partial replacement of sand and cement. During casting, the cylinders were mechanically vibrated using a table vibrator. After 24 hours, the specimens were demoulded and subjected to curing for 28 days in portable water. After curing, the 
cylindrical specimens were tested for split tensile strength using compression testing machine of $2000 \mathrm{kN}$ capacity.

\section{RESULT AND DISCUSSIONS}

The test results indicate that for mixtures prepared using up to $10 \%$ copper slag replacement, the compressive strength of concrete increased. However, for mixtures with S30 and S50 copper slag, the compressive strength decreased rapidly. Mixture S10 yielded the highest 28 day compressive strength of 56 $\mathrm{N} / \mathrm{mm} 2$ compared with $43.55 \mathrm{~N} / \mathrm{mm} 2$ for the control mixture, whereas the lowest compressive strength of $31.11 \mathrm{~N} / \mathrm{mm} 2$ was obtained for mixture S50 with 50\% copper slag. Still, the S50 values are greater than control mix. This reduction in compressive strength for concrete mixtures with high copper slag contents is due to increase in the free water content that results from the low water absorption characteristics of copper slag in comparison with sand. This causes a considerable increase in the workability of concrete and thus reduces concrete strength.

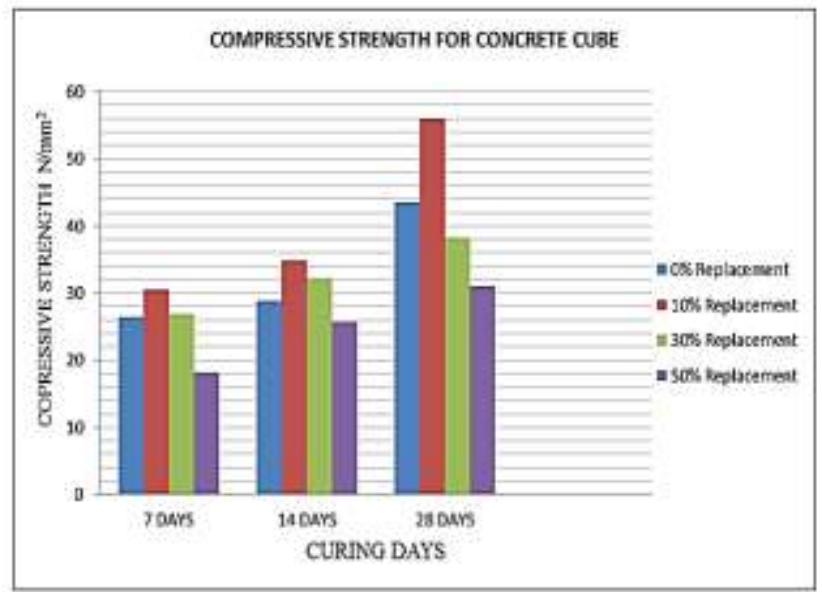

Fig 2. Brat chart in compressive strength for concrete cube

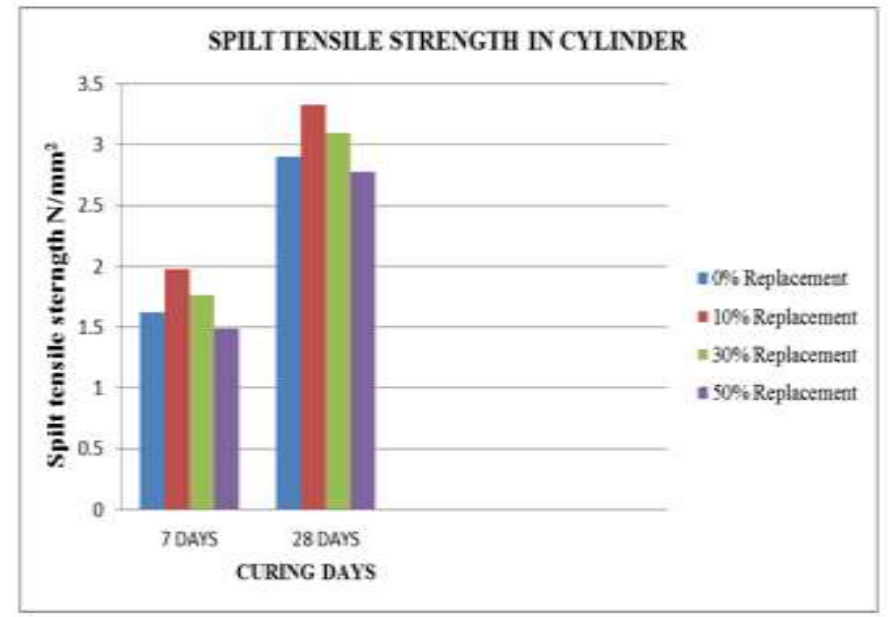

Fig 3. Bar chart for Spilt tensile test in cylinder

\section{REFERENCES}

[1]. Akihiko, Y. and Takashi, Y. "Study of utilization of copper slag as fine aggregate for concrete ", Ashikaya Kogyo Daigaku Kenkyu Shuroku, Vol. 23, pp. 79-85, 1996.

[2]. Al-Jabri, K. and Makoto Hisada. "Copper slag as sand replacement for high performance concrete ", Cement \& Concrete Composites, Vol. 31,pp. 483- 488, 2009.

[3]. Al-Jabri, K., Taha, R. and Al-Ghassani, M. "Use of copper slag and cement by-pass dust as cementitious materials " Cement, Concrete Aggregates, Vol. 24, No.1, pp. 7-12, 2005.

[4]. Al-Jabri, K.S., Abdullah, H., Al-Saidy and Ramzi Taha. "Effect ofcopper slag as a fine aggregate on the properties of cement mortars ND concrete ", Construction and Building Materials, Vol. 25, pp. 933-938,2011.

[5]. Al-Jabri, K.S., Taha, R.A., Al-Hashmi, A. and Al-Harthy, A.S. "Effectof copper slag and cement by-pass dust addition on mechanical properties of concrete ", Construction and building materials, Vol. 20,pp. 322-331, 2006.

[6]. Alpa, I. and Deveci, H. "Utilization of flotation wastes of copper slagas raw material in cement production ", Journal of hazard materials, Vol. 159, No. 2, pp. 390-395, 2008. 
[7]. Al-Jabri, K.S., Makoto Hisada, Abdulla, H.A. and Al-oraini, S.K. "Performance of high strength concrete made with copper slag as a fine aggregate ", Construction and building materials, Vol.23,pp. 2132-2140, 2009.

[8]. Arino, A.M. and Mobasher, B. "Effect of copper slag on the strength, and toughness of cementitious mixtures ", ACI Materials Journal,Vol. 96, No. 1, pp. 68-75, 1999. 